\title{
Omega-3 Fatty Acids and Cardiovascular Disease Risk: Do We Understand the Relationship?
}

\author{
M. VRABLÍK, M. PRUSÍKOVÁ, M. ŠNEJDRLOVÁ, L. ZLATOHLÁVEK \\ Third Department of Internal Medicine, First Medical Faculty of Charles University and General \\ University Hospital, Prague, Czech Republic
}

Received June 25, 2009

Accepted July 14, 2009

\section{Summary}

There is a large body of evidence documenting the effects of long-chain polyunsaturated fatty acids with the first double bond at the third position from methyl-terminal (so called omega-3 fatty acids (FAs)) on different components of cardiovascular disease (CVD) risk. However, it may seem the more answers on the topic we learn, the more questions remain to be elucidated. There are three levels of evidence documenting the impact of fish omega-3 FAs on CVD risk. Epidemiological data have shown unequivocally the increased intake of fish is associated with lower CVD morbidity and mortality. Numerous experimental studies have shown (almost always) positive effects of omega-3 FAs on lipoprotein metabolism, coagulation and platelet function, endothelial function, arterial stiffness etc. Most importantly, there are a few prospective clinical endpoint trials (DART, JELIS, GISSI Prevenzione and GISSI-HF) that have examined the impact of omega-3 FAs supplementation on cardiovascular outcomes in different patient populations. Recent meta-analyses of these and other clinical studies have yielded somewhat conflicting results. In this review we will summarize current evidence of omega-3 FAs effects on cardiovascular risk focusing on new data from recent clinical trials as well as possible practical implications for clinical practice.

\section{Key words}

Omega-3 fatty acids • EPA - DHA • Cardiovascular risk • Cardiovascular event $\bullet$ Omega-3 index

\section{Corresponding author}

Michal Vrablík, Third Department of Internal Medicine, General University Hospital, U Nemocnice 1, 12808 Prague 2, Czech Republic. Fax: +420 224962 946. E-mail: vrablikm@seznam.cz

\section{Introduction}

Long-chain polyunsaturated fatty acids with the first double bond at the third position from the methyl terminal (so called n-3 FAs or omega-3 FAs) can be found in plants and fish. The essential omega-3 FA is alpha-linolenic acid (ALA) that occurs in plants (walnuts, soybean, flaxseed and their oils). This FA is a precursor also for arachidonic acid, which is further metabolised giving rise to eikosanoids with multiple biological functions in the organism. ALA is a substrate for elongation and thus eicosapentaenoic (EPA) and docosaheaxaenoic (DHA) omega-3 FAs are being produced. The latter two can be found in larger quantities in fish meat or fish oil, respectively (salmon, mackerel, trout) (Nettleton 1991). As only less than $5 \%$ of ALA is converted to EPA and DHA in human organism, the dietary sources of these are also considered essential (Brenna 2002, Plourde and Cunnane 2007).

\section{Evidence of cardioprotective effects of omega-3 fatty acids}

There have been numerous studies on the impact of fish oil supplementation or fish consumption on the incidence of various forms of atherosclerotic cardiovascular disease. However, many of these studies were poorly designed, lacking proper control group or blinding with ill-defined amount and type of omega-3 FAs used in the intervention arms. Moreover, it is difficult to compare results of trials using dietary advice to those with a precisely defined dose of an omega-3 FAs 
Table 1. Documented cardioprotective properties of omega-3 fatty acids.

\begin{tabular}{ll}
\hline Omega-3FAs increase & Omega-3 FAs decrease \\
\hline HDL-cholesterol levels & $\begin{array}{l}\text { Triglyceride levels } \\
\text { Platelet aggregation and } \\
\text { adhesion }\end{array}$ \\
Arrhythmia threshold & Adiponectin levels \\
Arterial compliance & Inflammation (IL-6, TNF \\
Endothelium dependent & alpha) \\
vasodilation & Blood pressure and heart \\
Atherosclerotic plaque & rate \\
stability & Sympathetic nervous \\
Production of vaso- & system activity \\
\hline constrictive eikosanoids
\end{tabular}

HDL- high-density lipoprotein, IL-6 - interleukin 6, TNF-alphatumour necrosis factor alpha

supplement. And (as always when evaluating data from clinical trials) one must take into account the population that was studied and the data refer to. Despite all the above mentioned pitfalls, omega-3FAs belong to the best documented substances in cardiovascular medicine even though still with not entirely understood mechanisms of protective action.

Fish omega-3 FAs (namely EPA and DHA) posses a lot of properties that can explain their positive impact on cardiovascular events seen both in epidemiological and interventional studies. Table 1 shows some of the most important cardiovascular effects of fish omega-3 FAs. It is noteworthy EPA and DHA differ in their ability to promote various effects of omega-3 FAs supplementation. Obviously, the two occur always together in natural sources - fish meals and fish oil. However, as highly purified EPA and DHA became available, evidence documenting individual effects of EPA and DHA has been accumulated. Comparison of DHA and EPA effects on individual markers of CVD risk is shown in Table 2.

\section{Omega-3 FAs and cell membrane function}

There is a solid experimental evidence of different effects of fish omega-3 FAs on individual components of cardiovascular risk. These can be largely explained by very rapid incorporation of omega-3 FAs into cell membranes thus affecting function of cells and tissues with subsequent impact on production of various vasoactive eiosanoids and other mediators (Din et al. 2004). These effects can explain for example
Table 2. Comparison of EPA and DHA effects on cardiovascular risk factors.

\begin{tabular}{lcc}
\hline & EPA & DHA \\
\hline$\downarrow$ triglycerides & ++ & ++ \\
$\uparrow$ HDL & - & + \\
$\downarrow$ small dense LDL & - & + \\
$\downarrow$ blood pressure & $+/-$ & + \\
$\uparrow$ endothelial function & - & + \\
$\downarrow$ heart rate & - & + \\
$\downarrow$ platelet aggregability & + & ++ \\
$\downarrow$ platelet activation & + & - \\
$\uparrow$ fibrinolysis & - & - \\
$\uparrow$ glycemia & + & +- \\
$\downarrow$ immune response & - & $+/-$ \\
$\downarrow$ oxidative stress & + & + \\
\hline
\end{tabular}

improvement of endothelial dysfunction or direct influence of omega-3 FAs supplementation on the platelet function (Lee et al. 2006). It is also likely the replacement of saturated FAs from cell membranes of cardiomyocytes for omega-3 FAs may account for the antiarrhytmic effect of EPA and DHA observed in some studies (Woodman et al. 2003).

\section{Omega-3 FAs and lipid metabolism}

Both EPA and DHA play a role in modification of lipid and lipoprotein metabolism. They lower triglycerides by approximately 25 to $35 \%$. However, in cases of severe hypertriglyceridemia when TG levels exceed $5.5 \mathrm{mmol} / \mathrm{l}$, magnitude of the effect can reach $45 \%$ (Harris et al. 1997). Only DHA increases HDL cholesterol shifting the distribution of HDL subclasses towards larger $\mathrm{HDL}_{2}$ particles that are more active in reverse cholesterol transport (Mori 2000). Although, there is usually no significant change in LDL-cholesterol concentration associated with omega-3 FAs administration, DHA changes the distribution of LDL particle subfractions in favour of less atherogenic, large, buoyant LDLs (Mori 2000). On contrary, especially with high doses of omega-3 FAs used in the treatment of hypertriglyceridemia, LDL levels may rise by $10 \%$, this effect being even more pronounced in patients with extreme TG elevations at baseline (Harris et al. 1997, Harris 1997). This adverse effect of omega-3 FAs may be mediated mostly by DHA as EPA in moderate dose produced $10 \%$ LDL lowering in the JELIS trial (Yokoyama et al. 2007). The effects on plasma lipids 
\% change vs. baseline

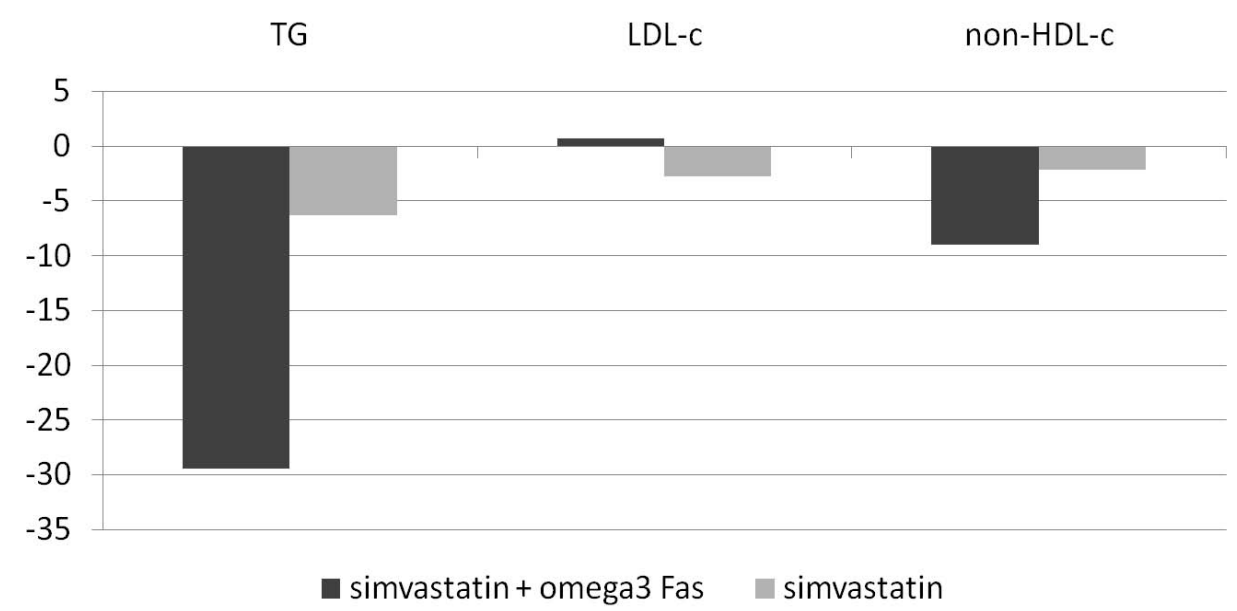

Fig. 1. Effect of $4 \mathrm{~g} / \mathrm{d}$ omega-3 FAs in combination with simvastatin in patients with elevated triglyceride levels (2.26-5.64 $\mathrm{mmol} / \mathrm{l}$ ) in the COMBOS Trial (data from Davidson et al. 2007). start to occur at daily doses of EPA and DHA of 2 to 4 grams. Very importantly, omega-3 FAs have synergistic and additive effects on plasma lipids when coadministered with statins as depicted by Fig. 1 (Davidson et al. 2007). Another practical implication of such studies is the proven safety of omega-3 FAs add on therapy to statins (Davidson et al. 2007, Yokoyama et al. 2007).

\section{Omega-3 FAs and hemodynamics}

In all studies of omega-3 FAs a decrease of heart rate has been described in the active treatment arms. The average fall of heart rate ranged from 3 to 3.7 beats per minute being more pronounced in DHA (Morris et al. 1993). In a study assessing the impact of omega-3 FAs on blood pressure control using 24-hour monitoring the average decrease of 5.8 and $3.3 \mathrm{~mm} \mathrm{Hg}$ for systolic and diastolic blood pressure, respectively, were observed (Mori et al. 1999). The mechanisms beyond this effect include membrane stabilizing effect, lowering the sensitivity of beta-adrenergic receptors as well as that of sympathetic nervous tone (Grimsgaard et al. 1998).

\section{Omega-3 FAs and platelet function}

Both DHA and EPA have profound effect on platelet function. Not only membrane stabilizing effect but also competition of omega-3 FAs for cyklooxygenase activity with arachidonic acid (more pronounced in DHA), which lowers production of platelet activating eicosanoids (e.g. tromboxane $\mathrm{A}_{2}$ ) play an important role (Larson et al. 2008). In a study in diabetic patients Woodman and co-workers demonstrated administration of highly purified EPA/DHA was associated with a decrease in platelet aggregability by $30 \%$ (Woodman et al. 2003). The platelet function modification effects are dose dependent and start with doses of omega-3 FAs greater than $2 \mathrm{~g}$ per day (Woodman et al, 2003). The platelet effects seem to be mediated mostly by EPA (Din et al. 2007).

\section{Omega-3 FAs and inflammation}

Another possibly cardioprotective action of omega-3 FAs can be modulation of immune response and anti-inflammatory properties. As demonstrated in vitro, DHA lowers cytoadhesive molecules expression on endothelial cells and monocytes (Mori and Beilin 2004). Similarly, levels of interleukin 6 , interleukin $1 \beta$ and tissue necrosis factor $\alpha$ decrease after EPA/DHA administration (Bhatnagar and Durrington 2003). However, in another work of the same authors no impact of omega-3 FAs supplementation on hsCRP in a cohort of diabetics was observed (Mori et al. 2003). Very high doses of omega-3FAs (i.e. $8 \mathrm{~g} / \mathrm{d}$ ) were associated with a significant reduction of inflammatory marker levels in patients with severe heart failure (Mehra et al. 2006).

There are a few other documented effects of omega-3 FAs supplementation on different pathways playing a role in the development of cardiovascular disease, e.g. fat tissue metabolism and adipokine production, insulin resistance, fibrinolysis etc. (Itoh et al. 2007, Mori et al. 2003, Grimsgaard et al. 1998) The evidence is usually less robust and sometimes inconsistent.

As we reviewed above, there exists very large documentation of mechanisms by which omega-3 FAs can protect arteries from development of atherosclerosis. Nevertheless, one must bear in mind that even the best experimental evidence of benefit associated with a therapy is not a proof of its impact on clinical events. Thus, for any treatment the most important is the data from well organized, randomised, placebo-controlled clinical trials and omega-3 FAs are not an exception. 


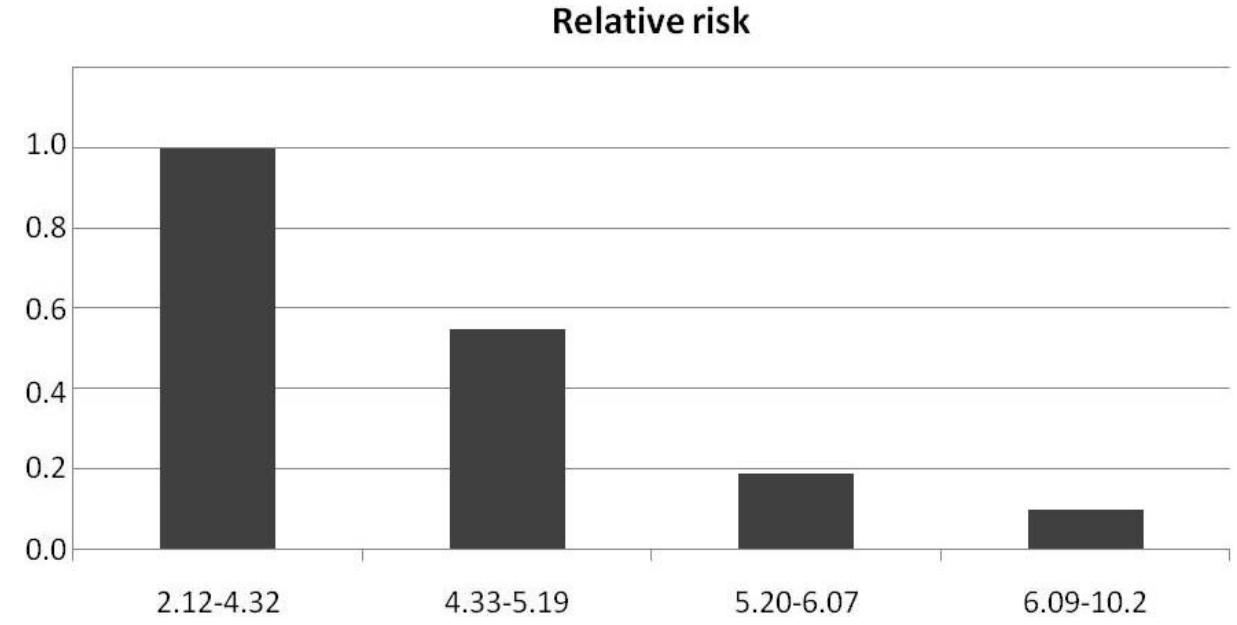

Fig. 2. Relative risk of sudden cardiac death according to omega-3 FAs blood concentration as a percentage of all fatty acids (data from Block et al. 2007).

\section{Omega-3 fatty acids and cardiovascular risk in the light of clinical trials}

Since the original epidemiological observations of low CVD mortality in populations with high consumption of fish there has been continuous interest of scientific and medical communities in the possibility of lowering CVD risk by omega-3FAs (Zhang et al. 1999). Thus, it is not surprising that the medical literature to date contains thousands of papers on the topic. As stated in the beginning of this review, the studies are frequently difficult to compare due to methodological and statistical issues, which also hamper the efforts of authors of metaanalyses.

In the past three years, at least four major metaanalyses of omega-3 FAs and their relationship to cardiovascular morbidity and mortality were published with not entirely concordant conclusions (Hooper et al. 2006, Wang et al. 2006, León et al. 2008, Lee et al. 2008). While three of them concluded that fish oils supplementation is associated with a decrease of the risk of cardiovascular events and CVD death rates, the newest and largest meta-analysis by León and co-workers failed to prove any benefits of omega-3 FAs on cardiovascular prognosis. A logical question would be, how it was possible the meta-analyses using the same data ended up with a different conclusion? The most likely reason is the selection of studies included into the subsequent analyses and new data that could not have been assessed previously.

In terms of cardiovascular efficacy and safety of omega-3 FAs there are three most important clinical studies: the DART study, the GISSI Prevenzione and GISSI-HF trials and the JELIS study.

In the Diet and Reinfarction Trial (DART), 2033 men after myocardial infarction were followed for two years. These were randomly assigned to a group instructed to increase fish intake to achieve daily consumption of EPA and DHA of approximately $900 \mathrm{mg}$ or to a control group that received no specific information. The intervention group experienced $29 \%$ reduction in all cause mortality and the incidence of reinfarction was reduced by $32 \%$ (Burr et al. 1989). The authors performed another analysis of the original cohort ten years after the initiation of the study. Surprisingly, despite the intervention group still had slightly higher intake of fish (not significantly compared to the controls in the follow-up), the positive impact of fish diet disappeared and the patients from the original intervention group showed even greater risk of cardiovascular death than original controls (unadjusted hazard 1.31). Authors themselves speculate this was likely due to the fact omega-3 FAs offer rather acute cardioprotection mediated by platelet function modification, anti-oxidative and anti-inflammatory properties and thus long term benefit could not have been demonstrated. Moreover, the intake of fish was similar in the two groups after the original DART study was terminated, which also attenuated any possible differences (Ness et al. 2002).

The second study that usually belongs to the core evidence in any meta-analysis is the Japan EPA Lipid Intervention Study (JELIS) (Yokoyama et al. 2007). It was a very large trial following 18645 patients with hyperlipidemia (more than 3500 of which had a history of a vascular event). The study subjects were randomly assigned to either statin alone or a combination of statin and $1.8 \mathrm{~g}$ of EPA daily. After 5 years, the combination treatment was associated with a significant reduction of the primary composite endpoint comprising death, revascularisation, myocardial infarction and unstable 
angina by $19 \%$ compared to the statin alone group. A post hoc analysis of the secondary prevention subgroup revealed similar benefit of the statin+EPA combination of cardiovascular outcomes in this subgroup in which relative risk was reduced by $23 \%$ (Matsuzaki et al. 2009). The greatest relative risk reduction of $53 \%$ experienced patients in primary prevention with increased triglyceride and decreased HDL-cholesterol levels (Saito et al. 2008).

The third study providing a substantial part of the data in the meta-analyses is the Gruppo Italiano per lo Studio della Sopravivenza nell'Infarto Miocardico (GISSI)-Prevenzione study (GISSI-Prevenzione Investigators 1999). 11323 survivors of myocardial infarction were randomized to $850 \mathrm{mg}$ of DHA/EPA daily or usual care. Treatment significantly reduced risk of death from any cause by $28 \%$ after only 4 months, being driven mainly by the lowering of sudden cardiac death risk by $45 \%$. The differences remained significant for the whole 3.5 year duration of the study. Effects of omega-3 FAs were studied by the same group in a population of heart failure patients (GISSI-HF Investigators 2008). 3494 patients with heart failure were randomized to $850 \mathrm{mg}$ of omega-3 FAs daily and 3481 received matching placebo. DHA/EPA administration reduced the risk of death from any cause by $9 \%$ $(\mathrm{p}=0.041)$ and hospitalization for cardiovascular reasons by $8 \%(p=0,009)$, which means 56 patients needed to be treated for 3.9 years to prevent one death.

The three cited studies clearly demonstrate the pitfalls of meta-analyses. The DART, JELIS and GISSI studies enrolled different patient populations with large differences in baseline cardiovascular risk. In the trials different types and doses of omega-3 FAs as well as different study designs were used. It is also noteworthy, that the follow-up analysis of the DART study reported increased risk of cardiovascular events, which attenuates the positive findings from the JELIS and GISSI trials when evaluated together.

\section{Omega-3 FAs: navigating the maze of evidence}

Even though the meta-analyses of omega-3 FAs impact on cardiovascular risk are sometimes controversial, the evidence of cardiovascular benefit associated with omega-3 FAs consumption is unequivocal. This fact is being reflected by guidelines of various expert societies including American Heart Association (Kris-Etherton et al. Circulation 2003),
American Diabetes Association (Buse et al. 2007) as well as the joint guidelines on cardiovascular prevention of nine European societies (Graham et al. 2007). All the guidelines in line with most meta-analyses and reports from well conducted clinical trials agree the evidence is particularly well-proven in secondary prevention and (although less robust) it is reliable in primary prevention setting, too.

For the primary prevention of cardiovascular events it is currently recommended to maintain the daily intake of DHA and EPA in the range of 300-600 mg. In secondary prevention higher dose of 900 to $1200 \mathrm{mg}$ a day is well supported by the evidence. For the reasons of triglyceride lowering even higher dose between 3000 and $4000 \mathrm{mg}$ of DHA and EPA is suggested.

The recommended intake of omega-3 FAs can be achieved by increased oily fish consumption; however, for the purpose of triglyceride lowering dietary supplements of concentrated EPA/DHA are usually necessary. A standardized capsulated concentrate of EPA and DHA as a prescription drug is also available in the USA and some European countries (Brunton and Collins 2007).

The future direction might be individualizing the recommendation according to the actual need of a particular patient based on the measurement of plasma concentration of omega-3 FAs. As reviewed by Albert and co-workers concentrations of omega-3 FAs in plasma are strong predictors of sudden cardiac death (Albert et al. 2002). Therefore, Harris has proposed a new marker of cardiovascular risk - an omega-3 index (Harris 2007). This index reflects the proportion of omega- 3 FAs in the membrane of red blood cells. Omega- 3 index exceeding $8 \%$ is associated with the lowest risk of cardiovascular events while levels below $4 \%$ are typically found in coronary artery disease patients (Block et al. 2007) (Fig. 2). Thus, omega-3 index may help identify those who would benefit most from omega-3 FAs supplementation.

\section{Conclusions}

Omega-3 FAs take part in a number of processes influencing the course of atherosclerotic vascular disease from initial functional changes to severe structural damage. Despite sometimes conflicting results of individual clinical trials as well as metaanalyses of omega-3 FAs impact on cardiovascular outcomes, the current evidence is sufficient to 
encourage intake of 500 and $1000 \mathrm{mg}$ of EPA/DHA daily in primary and secondary prevention of cardiovascular disease, respectively. In the future, more personalized recommendation based on assessment of individual omega-3 FAs needs (using e.g. omega-3 red blood cell index) would be possible.

\section{Conflict of Interest}

There is no conflict of interest.

\section{Acknowledgements}

This work was partly supported by the Research Project of the Ministry of Youth and Education of the Czech Republic No. 0021620807.

\section{References}

ALBERT CM, CAMPOS H, STAMPFER MJ, RIDKER PM, MANSON JE, WILLETT WC, MA J: Blood levels of longchain n-3 fatty acids and the risk of sudden death. N Engl J Med 346: 1113-1118, 2002.

BHATNAGAR D, DURRINGTON PN: Omega-3 fatty acids: their role in the prevention and treatment of atherosclerosis related risk factors and complications. Int J Clin Pract 57: 305-314, 2003.

BLOCK RC, HARRIS WS, REID KJ, SANDS SA, SPERTUS JA: EPA and DHA in blood cell membranes from acute coronary syndrome patients and controls. Atherosclerosis 197: 821-828, 2008.

BRENNA JT: Efficiency of conversion of alpha-linolenic acid to long chain n-3 fatty acids in man. Curr Opin Clin Nutr Metab Care 5: 127-132, 2002.

BRUNTON S, COLLINS N: Differentiating prescription omega-3-acid ethyl esters (P-OM3) from dietary-supplement omega-3 fatty acids. Curr Med Res Opin 23: 1139-1145, 2007.

BURR ML, FEHILY AM, GILBERT JF, ROGERS S, HOLLIDAY RM, SWEETNAM PM, ELWOOD PC, DEADMAN NM: Effects of changes in fat, fish, and fibre intakes on death and myocardial reinfarction: diet and reinfarction trial (DART). Lancet 2: 757-761, 1989.

BUSE JB, GINSBERG HN, BAKRIS GL, CLARK NG, COSTA F, ECKEL R, FONSECA V, GERSTEIN HC, GRUNDY S, NESTO RW, PIGNONE MP, PLUTZKY J, PORTE D, REDBERG R, STITZEL KF, STONE NJ: Primary prevention of cardiovascular diseases in people with diabetes mellitus. Circulation 115: 114-126, 2007.

DAVIDSON MH, STEIN EA, BAYS HE, MAKI KC, DOYLE RT, SHALWITZ RA, BALLANTYNE CM, GINSBERG $\mathrm{HN}$ : COMBination of prescription Omega-3 with Simvastatin (COMBOS) Investigators. Efficacy and tolerability of adding prescription omega-3 fatty acids $4 \mathrm{~g} / \mathrm{d}$ to simvastatin $40 \mathrm{mg} / \mathrm{d}$ in hypertriglyceridemic patients: an 8week, randomized, double-blind, placebo controlled study. Clin Ther 29: 1354-1367, 2007.

DIN JN, HARDING SA, VALERIO CJ, SARMA J, LYALL K, RIEMERSMA RA, NEWBY DE, FLAPAN AD: Dietary intervention with oil rich fish reduces platelet-monocyte aggregation in man. Atherosclerosis 197: 290-296, 2008.

DIN JN, NEWBY DE, FLAPAN AD: Omega 3 fatty acids and cardiovascular disease-fishing for a natural treatment. $B M J$ 328: 30-35, 2004.

GISSI-PREVENZIONE INVESTIGATORS. Dietary supplementation with n-3 polyunsaturated fatty acids and vitamin E after myocardial infarction: results of the GISSI-Prevenzione trial. Lancet 354: 447-455, 1999.

GRAHAM I, ATAR D, BORCH-JOHNSEN K, BOYSEN G, BURELL G, CIFKOVA R, DALLONGEVILLE J, DE BACKER G, EBRAHIM S, GJELSVIK B, HERRMANN-LINGEN C, HOES A, HUMPHRIES S, KNAPTON M, PERK J, PRIORI SG, PYORALA K, REINER Z, RUILOPE L, SANS-MENENDEZ S, OP REIMER WS, WEISSBERG P, WOOD D, YARNELL J, ZAMORANO JL: European guidelines on cardiovascular disease prevention in clinical practice: executive summary. Atherosclerosis 194: 1-45, 2007.

GRIMSGAARD S, BØNAA KH, HANSEN JB, MYHRE ES:. Effects of highly purified eicosapentaenoic acid and docosahexaenoic acid on hemodynamics in humans. Am J Clin Nutr 68: 52-59, 1998.

HARRIS WS: n-3 fatty acids and serum lipoproteins: human studies. Am J Clin Nutr 65 (Suppl): 1645s-1654s, 1997.

HARRIS WS, GINSBERG HN, ARUNAKUL N, SHACHTER NS, WINDSOR SL, ADAMS M, BERGLUND L, OSMUNDSEN K. Safety and efficacy of Omacor in severe hypertriglyceridemia. J Cardiovas Risk 4: 385-391, 1997. 
HOOPER L, THOMPSON RL, HARRISON RA, SUMMERBELL CD, NESS AR, MOORE HJ, WORTHINGTON HV, DURRINGTON PN, HIGGINS JP, CAPPS NE, RIEMERSMA RA, EBRAHIM SB, DAVEY SMITH G: Risks and benefits of omega 3 fats for mortality, cardiovascular disease, and cancer: systematic review. BMJ 332: 752 760, 2006.

ITOH M, SUGANAMI T, SATOH N, TANIMOTO-KOYAMA K, YUAN X, TANAKA M, KAWANO H, YANO T, AOE S, TAKEYA M, SHIMATSU A, KUZUYA H, KAMEI Y, OGAWA Y: Increased adiponectin secretion by highly purified eicosapentaenoic acid in rodent models of obesity and human obese subjects. Arterioscler Thromb Vasc Biol 27: 1918-1925, 2007.

KRIS-ETHERTON PM, HARRIS WS, APPEL LJ, American Heart Association Nutrition Committee: Fish consumption, fish oil, omega-3 fatty acids, and cardiovascular disease. Circulation 107: 2747-2757, 2003.

LARSON MK, ASHMORE JH, HARRIS KA, VOGELAAR JL, POTTALA JV, SPREHE M, HARRIS WS: Effects of omega-3 acid ethyl esters and aspirin, alone and in combination, on platelet function in healthy subjects. Thromb Haemost 100: 634-641, 2008.

LEE JH, O'KEEFE JH, LAVIE CJ, MARCHIOLI R, HARRIS WS: Omega-3 fatty acids for cardioprotection. Mayo Clin Proc 83: 324-332, 2008.

LEE KW, BLANN AD, LIP GY: Effects of omega-3 polyunsaturated fatty acids on plasma indices of thrombogenesis and inflammation in patients post-myocardial infarction. Thromb Res 118: 305-312, 2006.

LEÓN H, SHIBATA MC, SIVAKUMARAN S, DORGAN M, CHATTERLEY T, TSUYUKI RT: Effect of fish oil on arrythmias and mortality: systematic review. BMJ 337: 2931-2938, 2008.

MATSUZAKI M, YOKOYAMA M, SAITO Y, ORIGASA H, ISHIKAWA Y, OIKAWA S, SASAKI J, HISHIDA H, ITAKURA H, KITA T, KITABATAKE A, NAKAYA N, SAKATA T, SHIMADA K, SHIRATO K, MATSUZAWA Y; The JELIS Investigators: Incremental Effects of Eicosapentaenoic Acid on Cardiovascular Events in Statin-Treated Patients With Coronary Artery Disease. Circ J 2009 (in press).

MEHRA MR, LAVIE CJ, VENTURA HO, MILANI RV: Fish oils produce antiinflammatory effects and improve body weight in severe heart failure. J Heart Lung Transplant 25: 834-838, 2006.

MORI TA, BAO DQ, BURKE V, PUDDEY IB, BEILIN LJ: Docosahexaenoic acid but not eicosapentaenoic acid lowers ambulatory blood pressure and heart rate in humans. Hypertension 34: 253-260, 1999.

MORI TA, BURKE V, PUDDEY IB, WATTS GF, O'NEAL DN, BEST JD, BEILIN LJ: Purified eicosapentaenoic and docosahexaenoic acids have differential effects on serum lipids and lipoproteins, LDL particle size, glucose, and insulin in mildly hyperlipidemic men. Am J Clin Nutr 71: 1085-1094, 2000.

MORI TA, WOODMAN RJ, BURKE V, PUDDEY IB, CROFT KD, BEILIN LJ: Effect of eicosapentaenoic acid and docosahexaenoic acid on oxidative stress and inflammatory markers, in treated-hypertensive Type 2 diabetic subjects. Free Rad Biol Med 35: 772-781, 2003.

MORRIS MC, SACKS F, ROSNER B: Does fish oil lower blood pressure: a meta-analysis of controlled trials. Circulation 88: 523-533, 1993.

NESS AR, HUGHES J, ELWOOD PC, WHITLEY E, SMITH GD, BURR ML: The long-term effect of dietary advice in men with coronary disease: follow-up of the Diet and Reinfarction trial (DART). Eur J Clin Nutr 56: 512-518, 2002.

NETTLETON JA: Omega-3 fatty acids: comparison of plant and seafood sources in human nutrition. J Am Diet Assoc 91: 331-337, 1991.

PLOURDE M, CUNNANE SC: Extremely limited synthesis of long chain polyunsaturates in adults: implications for their dietary essentiality and use as supplements. Appl Physiol Nutr Metab 32: 619-634, 2007.

SAITO Y, YOKOYAMA M, ORIGASA H, MATSUZAKI M, MATSUZAWA Y, ISHIKAWA Y, OIKAWA S, SASAKI J, HISHIDA H, ITAKURA H, KITA T, KITABATAKE A, NAKAYA N, SAKATA T, SHIMADA K, SHIRATO K, JELIS Investigators, Japan: Effects of EPA on coronary artery disease in hypercholesterolemic patients with multiple risk factors: sub-analysis of primary prevention cases from the Japan EPA Lipid Intervention Study (JELIS). Atherosclerosis 200: 135-140, 2008.

THIES F, GARRY JM, YAQOOB P, RERKASEM K, WILLIAMS J, SHEARMAN CP, GALLAGHER PJ, CALDER PC, GRIMBLE RF: Association of n-3 polyunsaturated fatty acids with stability of atherosclerotic plaques: a randomised controlled trial. Lancet 361: 477-485, 2003. 
WANG C, HARRIS WS, CHUNG M, LICHTENSTEIN AH, BALK EM, KUPELNICK B, JORDAN HS, LAU J: N-3 fatty acids from fish or fish oil supplements, but not alpha-linolenic acid, bendit cardiovascular disease outcomes in primary-and secondary- prevention studies: a systematic review. Am J Clin Nutr 84: 5-17, 2006.

WOODMAN RJ, MORI TA, BURKE V, PUDDEY IB, BARDEN A, WATTS GF, BEILIN LJ: Effects of purified eicosapentaenoic acid and docosahexaenoic acid on platelet, fibrilolytic and vascular function in Type 2 diabetic patients. Atherosclerosis 166: 85-93, 2003.

YOKOYAMA M, ORIGASA H, MATSUZAKI M, MATSUZAWA Y, SAITO Y, ISHIKAWA Y, OIKAWA S, SASAKI J, HISHIDA H, ITAKURA H, KITA T, KITABATAKE A, NAKAYA N, SAKATA T, SHIMADA K, SHIRATO K, Japan EPA lipid intervention study (JELIS) Investigators: Effects of eicosapentaenoic acid on major coronary events in hypercholesterolaemic patients (JELIS): a randomized open-label, blinded endpoint analysis Lancet 369: 1090-1098, 2007.

ZHANG J, SASAKI S, AMANO K, KESTELOOT H: Fish consumption and mortality from all causes, ischemic heart disease, and stroke: an ecological study. Prev Med 28: 520-529, 1999. 